\title{
Drugs in the treatment of obesity: sibutramine, orlistat and rimonabant
}

\author{
Miguel A Rubio ${ }^{1, *}$, Manuel Gargallo², Ana Isabel Millán ${ }^{3}$ and Basilio Moreno ${ }^{3}$ \\ 'Department of Endocrinology and Nutrition, Hospital Clínico San Carlos, c/ Martín Lagos s/n, 28040 Madrid, \\ Spain: ${ }^{2}$ Department of Endocrinology and Nutrition, Hospital Virgen de la Torre, Madrid, Spain: ${ }^{3}$ Department of \\ Endocrinology and Nutrition, Hospital Gregorio Marañón, Madrid, Spain
}

Submitted 8 November 2006: Accepted 22 June 2007

\begin{abstract}
Background: Modification of lifestyle is the main therapeutical approach in the treatment of obesity, but use to fail on long terms of time. Addition of anti-obesity drugs allows keeping the weight loss during years and improving obesity-related comorbidities.

Methods: This review is an actualisation on efficacy, safety and tolerability of the approved drugs on the long-term treatment of obesity (orlistat and sibutramine). New indications and effects of their use far beyond the weight loss are as well commented. Finally, potential benefits of the administration of CB1 antagonist rimonabant on the weight loss and cardiometabolic risk factors are analysed in detail.

Discussion: A decade of experience on the use of orlistat and sibutramine has demonstrated their higher efficacy on the weight loss when compared to placebo either on adult or teenage population as well as safety and tolerability on longterm administration. Beneficial effects on the lipid profile, glycosilated haemoglobin on diabetic patients, blood pressure and levels of inflammatory cytokines, contribute to decrease the cardiovascular risk on obese patients. Phase III clinical trials using rimonabant show additional benefits to the expected weight loss, mainly reducing visceral fat and cardiometabolic risk factors.

Conclusion: Pharmacological treatment of obesity must be considered as a therapeutical tool that has to be used together with long-term lifestyle changes, contributing to the body weight reduction as well as to the improvement of the cardiometabolic risk related to obesity.
\end{abstract}

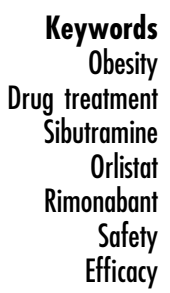

The increased overweight and obesity prevalence observed in industrialised countries, which nowadays affects two-thirds of their population, determines a higher risk of developing type 2 diabetes mellitus and cardiovascular disease-related death.

Changing lifestyle habits is still the main cornerstone of the therapy for obesity, but improvement of cardiometabolic parameters as hyperglycaemia, insulin resistance, abdominal obesity and atherogenic dyslipidaemia must be major targets, as well as weight reduction.

Moderate weight loss (approximately 5-10\% of body weight) by lifestyle changes improves obesity-related comorbidities. Unfortunately, this medical approach is not long lasting and weight regain is often seen. Drugs that prevent weight regain appear necessary in obesity treatment.

Safety on anti-obesity agents have historically been of concern due to severe side-effects that contraindicated their use. Actually, sibutramine and orlistat are the only authorised anti-obesity drugs in Europe. Efficacy and safety of other molecules are currently being evaluated on phase II-III clinical trials ${ }^{1}$, but only one of them, rimonabant, will be a real therapeutical option in the next months.

Safety and tolerability of these drugs, as well as their efficacy on cardiometabolic risk factors will be analysed in this article.

\section{Sibutramine}

The mode of action of sibutramine is centrally mediated by a serotonin and epinephrine reuptake inhibition, which enhances satiety and decreases caloric intake. Sibutramine has shown marked thermogenic properties in laboratory animals but is not significant in human beings.

The usefulness of sibutramine in obesity treatment has been widely demonstrated in multiple prospective randomised trials. Probably the most significant is the 
STORM study (Sibutramine Trial of Obesity Reduction and Maintenance $)^{2}$ that demonstrated its utility on weight reduction as well as on weight loss maintenance. A higher weight loss in sibutramine-treated obese patients of approximately $4.5 \mathrm{~kg}$ compared to placebo has been show in long-term studies in different meta-analyses ${ }^{3,4}$. Far beyond its efficacy, effects in selective obese groups and clinical use are discussed below.

\section{Obese adolescents}

Some clinical trials using sibutramine ( 10 or $15 \mathrm{mg} \mathrm{day}^{-1}$ ) have shown promising results achieving weight loss in obese adolescents $^{5-7}$, but the samples were very small and gave rise to some safety concerns about the $15 \mathrm{mg}$ day $^{-1}$ dose.

Recently, a multicentre randomised trial from the Sibutramine Adolescent Study Group ${ }^{8}$, including 368 adolescent treated with sibutramine uptitrated to $15 \mathrm{mg}$ during 1 year, confirmed a statistically significant decrease in body mass index (BMI) and weight in the sibutramine group vs. placebo. In relation to adverse events, only small, although statistically significant, differences in blood pressure and heart rate were described, similar to observations previously reported in adults.

Therefore, sibutramine could become an acceptable additional therapeutic option in obese adolescents, considering the same recommendations as in adults treated with sibutramine, to monitor blood pressure and pulse rate.

\section{Binge eating}

Efficacy of sibutramine on binge eating disorder has been recently evaluated in controlled clinical trials. Two of them showed positive results on three of the final outcomes after 12 weeks treatment with sibutramine $\left(10 \mathrm{mg} \mathrm{day}^{-1}\right)$ : weight reduction, decrease in binge eating episodes and psychiatric symptoms ${ }^{9,10}$. Subclinical binge eating and clinical results with sibutramine treatment was evaluated on the third trial where a greater weight reduction was observed when compared to placebo, but failed to demonstrate improvement on the psychiatric symptoms ${ }^{11}$.

\section{Very-low-calorie diets}

Very-low-calorie diets (VLCDs) are used to promote shortterm weight loss in obese patients. However, long-term maintenance of weight loss is generally poor. Weight loss achieved after a 3-month VLCD is more effectively improved and maintained with sibutramine plus a diet and exercise programme than with placebo over a followup period of $12-18$ months $^{12,13}$ (Table 1). These results agree with those obtained in the STORM study ${ }^{2}$, which demonstrated maintenance of weight reduction with sibutramine than with a conventional dietetic approach.
Table 1 Randomised trials: very-low-calorie-diets plus sibutramine

\begin{tabular}{lll}
\hline & Apfelbaum et al. ${ }^{11}$ & Mathus-Vliegen et al. ${ }^{12}$ \\
\hline$n$ (Sib/PI) & $81 / 78$ & $94 / 95$ \\
Dose Sib & $10 \mathrm{mg}$ & $10 \mathrm{mg}$ \\
Follow-up & 12 months & $6 / 12 / 18$ months \\
Results Sib vs. PI & Keep $100 \%$ weight & Keep $>80 \%$ weight lost: \\
& loss: $75 \%$ vs. & $70 / 51 / 30 \%$ vs. 48/31/ \\
& $42 \%(P<0.01)$ & $20 \%(P<0.05)$ \\
\hline
\end{tabular}

Sib - sibutramine; $\mathrm{Pl}$ - placebo.

\section{Type 2 diabetes mellitus}

Type 2 diabetes obese patients must be specially considered due to their increased morbidity and mortality and additional difficulties to obtain weight reduction. Sibutramine usefulness in this group of patients has recently been evaluated on different trials ${ }^{14,15}$. More than $50 \%$ of diabetic subjects receiving sibutramine achieve $>5 \%$ weight loss and over 20\% achieved $>10 \%$ weight loss. As expected, higher weight losses are related to an improvement on glycosylated haemoglobin, triglycerides and high-density lipoprotein (HDL) cholesterol levels. Moderate but significant higher diastolic blood pressure and heart rate were observed as side-effects, recommending careful evaluation and control of these parameters in this subgroup of obese patients.

\section{Metabolic effects}

Sibutramine exerted favourable effects on lipids in most trials, especially on HDL cholesterol and triglycerides, as well as on the total: HDL cholesterol ratio. Furthermore, this drug seems to favourably influence adipocytokines; it reduces serum leptin and resistin levels and increases adiponectin levels ${ }^{16}$.

\section{Safety and adverse events}

Long-term sibutramine treatments have revealed beneficial effects on the risk to develop primary pulmonary hypertension and heart valve dysfunction, as observed in previous serotonin agonist drugs like D-fenfluramine.

Controversy still remains regarding the impact of changes on blood pressure and heart rate, mainly because hypertension is one of the obesity-associated diseases that is expected to improve after obesity therapy.

Sibutramine increases systolic and diastolic blood pressure by $2-3$ and $1-2 \mathrm{mmHg}$, respectively, and medium heart rate augments by $4-5$ beats per minute ${ }^{17,18}$. Anyway, the potential benefits of weight loss outweighed the small increases in heart rate and blood pressure, as shown in the largest study that included 2225 subjects with cardiovascular risk factors, from a primary care setting ${ }^{19}$.

Enlarging of the QT segment and arrhythmia has been recently reported in patients treated with sibutramine ${ }^{20}$. Caution must be taken to avoid the use of sibutramine in 
patients with long QT syndrome, or treated with drugs related to the increase in the QT segment until safety data are available.

Questions concerning cardiovascular outcomes will be clarified with the SCOUT (Sibutramine Cardiovascular Morbidity/Mortality Outcomes Trial) study results. This clinical trial has been performed over 9000 cardiovascular risk obese patients randomised to sibutramine or placebo plus lifestyle changes, followed up for 5 years. Primary outcomes include the incidence of non-fatal myocardial infarction, non-fatal stroke, resuscitated cardiac arrest and cardiovascular death.

The most common side-effects associated with sibutramine use are mild and usually well tolerated: mouth dryness, constipation, headache and insomnia. Patient must withdraw treatment if mean blood pressure increases over $10 \mathrm{mmHg}$ or if heart rate augments by more than 10 beats per minute. Although the evidence of increased risk for cardiovascular or cerebrovascular events has not yet been clearly demonstrated, sibutramine should not be given to patients with uncontrolled hypertension or to patients with a known heart disease or stroke.

\section{Orlistat}

Orlistat is a potent inhibitor of pancreatic and gastric lipases that acts locally in the gut lumen and is minimally absorbed. Orlistat inhibits dietary triglycerides hydrolysis by $30 \%$; hence they pass into the stool, thus reducing total calorie intake.

A mean weight loss of $2.8-3.2 \mathrm{~kg}$ reduction additional to placebo, as well as significant improvement of blood pressure, lipids and metabolic control in diabetes have been described in meta-analysis ${ }^{21-23}$. Pooled data from randomised trials and from the open-label study X-PERT ${ }^{24}$ have shown that a weight loss of $>5 \%$ at 3 months is an accurate predictor of sustained improvements in weight in the long term.

\section{Cardiovascular risk factors}

Other than weight loss, orlistat has demonstrated beneficial effects on cardiovascular risk factors associated with obesity. Reduction on triglycerides and low-density lipoprotein (LDL) cholesterol detected on orlistat-treated patients is $10-12 \%$ higher than expected of the weight reduction. This fact is explained by the $25 \%$ reduction on the intestinal cholesterol absorption induced by the drug $^{25}$.

Diminution on intestinal lipid flux has been related to a decrease in the intra-abdominal fat content, $44 \%$ over the observed with a comparable weight reduction induced by diet alone ${ }^{26,27}$.

Other beneficial effects secondary to the weight reduction induced by orlistat include the C-reactive pro- tein, postprandial lipaemia, atherogenic lipoproteins and adipokines (interleukin- 6 and $\alpha$-tumour necrosis factor) reduction as well as adiponectin augment ${ }^{28,29}$. The degree of these findings and their clinical impact is yet to be evaluated. Otherwise, reduction on lipid content in organs such as the liver, improving steatosis, has also been demonstrated after treatment with orlistat ${ }^{30}$.

\section{Type 2 diabetes mellitus}

Weight loss on diabetic patients treated with orlistat is lower than that obtained in non-diabetic patients. Significant reductions in fasting glucose, glycosylated haemoglobin, total and LDL cholesterol and triglycerides are observed ${ }^{31}$.

Beneficial effect on glycaemic control is better than that expected by weight reduction itself. Two theories try to explain this fact based on a probable improvement on insulin sensitivity induced by orlistat ${ }^{32}$, by decreasing the lipid content in insulin-sensitive tissues (as liver and muscle) or increasing glucagon-like peptide 1 levels, as an incretin-like action ${ }^{33}$.

Long-term safety and efficacy of orlistat use have been proved on the randomised, placebo-controlled trial XENDOS (XENical in the prevention of Diabetes in Obese Subjects ${ }^{24}$ where 3305 obese patients were randomised to lifestyle changes plus either orlistat or placebo, for 4 years. The cumulative incidence of diabetes was 9.0\% with placebo and $6.2 \%$ with orlistat, corresponding to a risk reduction of $37.3 \%(P=0.0032)$. Treatment with orlistat resulted in significant improvements in cardiovascular risk factors that were sustained throughout the study, including blood pressure, waist circumference and lipids.

\section{Adolescents}

Different clinical trials have shown orlistat to be a safe, tolerable and effective therapeutic option in obese adolescents $^{34,35}$. Due to these characteristics, orlistat has recently been approved by the FDA for the treatment of obesity of children and teens from 12 to 16 years old.

\section{Side-effects}

The adverse effects are almost entirely related to the intestinal tract. Although the adverse events are not serious, they can be embarrassing; orlistat can be associated with increased defecation, fatty/oily stools, leaking of oil from the rectum, faecal urgency and faecal incontinence. Described side-effects were transient during the first treatment weeks and normally do not lead to drug discontinuation.

Orlistat can decrease fat-soluble vitamins, but remained within its reference range ${ }^{24}$. This risk is mitigated by an adequate diet or, exceptionally, by the daily intake of a multiple vitamin. 


\section{Rimonabant}

The endocannabinoid system acts as a neuromodulator that takes part in many physiological processes, including energy balance regulation and adipocyte secretion. Central and peripheral mechanisms are involved, whose action is mediated through two identified cannabinoid (CB) receptor subtypes, CB1 and CB2.

The CB1 receptor is located in the brain, adipose tissue, lung, intestine, muscle and liver as well as in the sympathetic nodes, heart and urinary bladder. So, they are widespread all over the organism. CB2 receptors are expressed in the immune system and they do not seem to be related to energetic metabolism ${ }^{36}$. The endocannabinoid system is usually over-expressed in obese subjects and responds to external stimuli as physical activity and food intake.

Rimonabant is a selective CB1 receptor blocker, able to disrupt central and peripheral endocannabinoid tone that determines reduction of food intake and regulation of adipocyte secretion. This effect takes part in the central nervous system as well as in peripheral terminals as gastrointestinal tract and muscle tissue (Table 2). Weight reduction is the final clinical effect.

\section{Clinical trials}

The Rimonabant-in-Obesity (RIO) programme consists of four 1-2-year phase III trials, RIO-Europe, RIO-Lipids, RIO-North America and RIO-Diabetes, designed to assess the efficacy and safety of rimonabant in the treatment of multiple cardiometabolic risk factors in 6600 overweight/ obesity patients. Assignment of medication was similar in all RIO trials. Subjects were randomised to receive rimonabant $20 \mathrm{mg} \mathrm{day}^{-1}$, rimonabant $5 \mathrm{mg} \mathrm{day}^{-1}$ or placebo for 1 year.

The first published clinical trial, named RIO-Europe ${ }^{37}$, enrolled obese subjects with BMI $>30 \mathrm{~kg} \mathrm{~m}^{-2}$, or $>27 \mathrm{~kg} \mathrm{~m}^{-2}$ with a comorbidity, defined as hypertension or dyslipidaemia. One year later, significant weight reduction was observed: $67 \%$ of those who completed the trial lost $5 \%$ of the initial weight and $49 \%$ lost $10 \%$. In

Table 2 Central and peripheral results of CB1 blockade in regulation of food intake and peripheral metabolism

\begin{tabular}{ll}
\hline Site of action & \multicolumn{1}{c}{ Mechanisms } \\
\hline $\begin{array}{l}\text { Hypothalamus/nucleus accumbens } \\
\text { Gastrointestinal tract }\end{array}$ & $\begin{array}{l}\text { Decrease in food intake } \\
\text { Decrease in food intake } \\
\text { (satiating signals) } \\
\text { Decrease in lipogenesis } \\
\text { Improves dyslipidemia } \\
\text { Increased glucose tolerance } \\
\text { Increased adiponectin } \\
\text { Increase in glucose-uptake } \\
\text { (less insulin-resistance) } \\
\text { Muscle }\end{array}$ \\
Liver & \\
\hline
\end{tabular}

CB1 - cannabinoid receptor subtype 1. addition, different components of the metabolic syndrome improved, including decrease in glycaemic and insulinaemic levels and healthier lipid profiles (reduction on triglycerides and increase in HDL cholesterol) compared to the placebo-treated group.

A second study, RIO-Lipids ${ }^{38}$, was performed in 1036 obese or overweight untreated dyslipidaemic. Results of this study showed improvement on the lipid profile as well as weight reduction $(3.1 \mathrm{~kg}$ in the rimonabant $5 \mathrm{mg}$ group and $6.9 \mathrm{~kg}$ in the rimobabant $20 \mathrm{mg}$ group) and waist circumference decrease $(7.1 \mathrm{~cm}$ in the rimonabant $20 \mathrm{mg}$ group). HDL cholesterol increased by $23.4 \%$, and triglycerides diminished by $15.8 \%$ in the $20 \mathrm{mg}$ rimonabant group. Improvements in HDL-C and triglycerides levels with rimonabant over 1 year, compared with body weight, were beyond that attributable to weight loss alone. The C-reactive protein levels were lower in the high-dose rimonabant group (27\% reduction vs. 11\% for placebo, $P=0.007)$. Rimonabant $20 \mathrm{mg}$ also increased adiponectin levels by $57.7 \%$, a change that was partly independent of weight loss alone.

Metabolic syndrome prevalence changed from $52.9 \%$ in the beginning of the study to $25.8 \%$ after follow up on the $20 \mathrm{mg}$ rimonabant group.

The RIO-Diabetes ${ }^{39}$ study, which enrolled 1047 type 2 diabetes mellitus treated on monotherapy, was designed to explore effects of rimonabant on glucose metabolism. At the end of 1 year, therapy with rimonabant $20 \mathrm{mg}$ was associated with an average weight loss of $5.3 \mathrm{~kg}$, compared with $1.4 \mathrm{~kg}$ in the placebo group. Glycosylated haemoglobin levels were decreased by $0.6 \%$ in the rimonabant $20 \mathrm{mg}$ group from a baseline level of $7.3 \%$, but were increased in the placebo group by $0.1 \%$. Remarkably, $43 \%$ of all subjects treated with rimonabant achieved an optimal glycosylated haemoglobin level of $<6.5 \%$, compared with just $21 \%$ of those receiving placebo.

The RIO-North America ${ }^{40}$ study enrolled 3045 obese patients. The aim of the study was to evaluate whether weight loss achieved with rimonabant could be maintained after withdrawal of the drug. After 1 year of randomised design as in the other RIO trials, subjects in the two rimonabant groups underwent a second randomisation, either to continue receiving their previously assigned dose of rimonabant or to be switched to a matching placebo. Weight loss after the first year was similar to previous RIO trials $\left(-6.3 \mathrm{~kg}\right.$ for $20 \mathrm{mg} \mathrm{day}^{-1}$ ). After 2 years, subjects who followed treated with rimonabant $20 \mathrm{mg} \mathrm{day}^{-1}$ lost an average of $7.4 \mathrm{~kg}$, whereas those subjects re-randomised to placebo had regained much of their weight. The prevalence of the metabolic syndrome declined with rimonabant $20 \mathrm{mg} \mathrm{day}^{-1}$ (34.8-21.1\%) compared with placebo (31.7-29.2\%). Lastly, the observed effects at 1 year in levels of HDL cholesterol, triglycerides, fasting insulin and in HOMA-IR (homeostatic model assessment-insulin resistance) in 
patients receiving $20 \mathrm{mg}$ of rimonabant were approximately twice that attributable to concomitant weight loss alone.

The ongoing STRADIVARIUS trial (Strategy To Reduce Atherosclerosis Development InVolving Administration of Rimonabant - the Intravascular Ultrasound Study) ${ }^{41}$ will determine if rimonabant $20 \mathrm{mg} \mathrm{day}^{-1}$ administered during 18-20 months could reduce the progression of coronary atherosclerosis, as assessed by intravascular ultrasound (IVUS), when administered in patients with abdominal obesity associated with current smoking and/or metabolic syndrome, and in whom a clinically indicated coronary angiography reveals a $20-50 \%$ stenosis.

\section{Safety and tolerability}

Rimonabant treatment was well tolerated. The most common adverse effects were mild nausea and diarrhoea, probably related to gastrointestinal CB1 receptors blockade. Depressed mood, anxiety, agitation and sleep disorders were the adverse events involved in some cases of drug withdrawal.

The analysis of the published bibliography shows that rimonabant $\left(20 \mathrm{mg} \mathrm{day}^{-1}\right.$ ) appears to be a good new choice in the treatment of obesity and metabolic syndrome with a dual mechanism: reducing weight and improving metabolic comorbidities of obesity and possibly improving the cardiometabolic profile of obese patients.

\section{Concluding remarks}

As in other chronic illnesses, certain resistance on lifelasting treatment is at hand, firstly due to the stigmatisation of considering obesity as a sickness related to unhealthy habits and secondly because in most of the countries this kind of treatment is not financed by the National Health System; hence they become unreachable to most patients with low economical status, where obesity is more prevalent.

To date, available drugs for the treatment of obesity are safe and effective in allowing a decrease in body weight in a moderate range (5-10\% initial body weight) for years, with additional properties to control associated cardiometabolic risks. However, these benefits appear only in patients who undergo long-term treatments. These questions are a matter of discussion, because in most controlled clinical trials, roughly half of the patients withdraw due to lack of efficacy and/or presence of sideeffects. This situation could be partially explained by the fact that intensive lifestyle changes were not achieved in most of these studies. Greater treatment adherence and more advantageous results could be accomplished if effective behaviour modification is acquired ${ }^{42}$. Another bias present in these clinical trials concerns the exclusion of patients on the risk of developing side-effects. Presence of hypertension, anxiety or other mood disorders is quite common in obese patients, representing a handicap on sibutramin or rimonabant use in clinical practice.

In short, the lack of financial coverage, potential contraindications, the presence of certain adverse effects and the absence of expected efficacy in some cases result in a large number of patients expecting the benefits of longterm pharmacological treatment.

\section{Acknowledgements}

Conflict of interest declaration: None.

Authorship responsibilities: All co-authors contributed equally in writing of this paper.

\section{References}

1 Halford JC. Obesity drugs in clinical development. Current Opinion in Investigational Drugs 2006; 7: 312-18.

2 James WP, Astrup A, Finer N, Hilsted J, Kopelman P, Rossner $\mathrm{S}$, et al. Effect of sibutramine on weight maintenance after weight loss: a randomised trial. STORM Study Group (Sibutramine Trial of Obesity Reduction and Maintenance). Lancet 2000; 356: 2119-25.

3 Padwal R, Li SK, Lau DCW. Long-term pharmacotherapy for overweight and obesity: a systematic review and metaanalysis of randomized controlled trials. International Journal of Obesity 2003; 27: 1437-46.

4 Li Z, Maglione M, Tu W, Mojica W, Arterburn D, Shugarman LR, et al. Meta-analysis: pharmacologic treatment of obesity. Annals of Internal Medicine 2005; 142: 532-46.

5 Godoy-Matos A, Carraro L, Vieira A, Oliveira J, Guedes EP, Mattos L, et al. Treatment of obese adolescents with sibutramine: a randomized, double-blind, controlled study. Journal of Clinical Endocrinology and Metabolism 2005; 90: $1460-5$.

6 Berkowitz RL, Wadden TA, Tershakovec AM, Cronquist JL. Behavior therapy and sibutramine for the treatment of adolescent obesity. A randomized controlled trial. Journal of the American Medical Association 2003; 289: 1805-12.

7 Reisler G, Tauber T, Afriat R, Bortnik O, Goldman M. Sibutramine as an adjuvant therapy in adolescents suffering from morbid obesity. Israel Medical Association Journal 2006; 8: 30-2.

8 Berkowitz RI, Fujikova K, Daniels SR, Hopping AG, Owen S, Perry AC, et al. Effects of sibutramine treatment in obese adolescents. A randomized trial. Annals of Internal Medicine 2006; 145: 81-90.

9 Appolinario JC, Bacaltchuk J, Sichieri R, Claudino AM, Godoy-Matos A, Morgan C, et al. A randomized, doubleblind, placebo-controlled study of sibutramine in the treatment of binge-eating disorder. Archives of General Psychiatry 2003; 60: 1109-16.

10 Milano W, Petrella C, Casella A, Capasso A, Carrino S, Milano L. Use of sibutramine, an inhibitor of the reuptake of serotonin and noradrenaline, in the treatment of binge eating disorder: a placebo-controlled study. Advances in Therapy 2005; 22: 25-31.

11 Bauer C, Fischer A, Keller U. Effect of sibutramine and of cognitive-behavioural weight loss therapy in obesity and subclinical binge eating disorder. Diabetes, Obesity and Metabolism 2006; 8: 289-95. 
12 Apfelbaum M, Yague P, Ziegles O, Hanotin C, Thomas F, Leutenegger E. Long-term maintenance of weight loss after a very-low-calorie diet: a randomized blinded trial of the efficacy and tolerability of sibutramine. American Journal of Medicine 1999; 106: 179-84.

13 Mathus-Vliegen EM, Balance Study Group. Long-term maintenance of weight loss with sibutramine in a GP setting following a specialist guided very-low-calorie diet: a double-blind, placebo-controlled, parallel group study. European Journal of Clinical Nutrition 2005; 59(Suppl. 1): S31-9.

14 Vettor R, Serra R, Fabris R, Pagano C, Federspil G. Effect of sibutramine on weight management and metabolic control in type 2 diabetes: a meta-analysis of clinical studies. Diabetes Care 2005; 28: 942-9.

15 Norris SL, Zhang X, Avenell A, Gregg E, Schmid CH, Lau J. Pharmacotherapy for weight loss in adults with type 2 diabetes mellitus. Cochrane Database Systematic Reviews 2005; 1: CD004096.

16 Filippatos TD, Kiortis DN, Liberopoulos EN, Mikhailidis DP, Elisaf MS. A review of the metabolic effects of sibutramine. Current Medical Research and Opinion 2005; 21: 457-68.

17 Jordan J, Scholze J, Matiba B, Wirth A, Hauner H, Sharma AM. Influence of sibutramine on blood pressure: evidence from placebo-controlled trials. International Journal of Obesity Related Metabolic Disorders 2005; 29: 509-16.

18 Kim SH, Lee YM, Jee SH, Nam CM. Effect of sibutramine on weight loss and blood pressure: a metaanalysis of controlled trials. Obesity Research 2003; 11: 1116-23.

19 Gaciong Z, Placha G. Efficacy and safety of sibutramine in 2225 subjects with cardiovascular risk factors: short-term, open-label, observational study. Journal of Human Hypertension 2005; 19: 737-43.

20 Harrison-Woolrych M, Clark DW, Hill GR, Rees MI, Skinner JR. QT interval prolongation associated with sibutramine treatment. British Journal of Clinical Pharmacology 2006; 61: 464-9.

21 O'Meara S, Riemsma R, Shirran L, Mather L, ter Riet G. A systematic review of the clinical effectiveness of orlistat used for the management of obesity. Obesity Reviews 2004; 5: 51-68.

22 Padwal R, Li SK, Lau DCW. Long-term pharmacotherapy for overweight and obesity: a systematic review and metaanalysis of randomized controlled trials. International Journal of Obesity 2003; 27: 1437-46.

23 Hutton B, Fergusson D. Changes in body weight and serum lipid profile in obese patients treated with orlistat in addition to a hypocaloric diet: a systematic review of randomized clinical trials. American Journal of Clinical Nutrition 2004; 80: 1461-8.

24 Toplak H, Ziegler O, Keller U, Hamann A, Godin C, Wittert $\mathrm{G}$, et al. X-PERT: weight reduction with orlistat in obese subjects receiving a mildly or moderately reduced-energy diet. Early response to treatment predicts weight maintenance. Diabetes, Obesity and Metabolism 2005; 7 . 699-708.

25 Mittendorfer B, Ostlund RE, Patterson BW, Klein S. Orlistat inhibits dietary cholesterol absorption. Obesity Research 2001; 9: 599-604.

26 Tiikkainen M, Bergholm R, Rissanen A, Aro A, Salminen I, Tamminen M, et al. Effects of equal weight loss with orlistat and placebo on body fat and serum fatty acid composition and insulin resistance in obese women. American Journal of Clinical Nutrition 2004; 79: 22-30.

27 Torgerson JS, Hauptman J, Boldrin MN, Sjostrom L. XENical in the Prevention of Diabetes in Obese Subjects (XENDOS) Study: a randomized study of orlistat as an adjunct to lifestyle changes for the prevention of type 2 diabetes in obese patients. Diabetes Care 2004; 27: 155-61.

28 Hsieh CJ, Wang PW, Liu RT, Tung SC, Chien WY, Chen JF, et al. Orlistat for obesity: benefits beyond weight loss. Diabetes Research and Clinical Practice 2005; 67: $78-83$.

29 Sutera PM, Marmiera G, Veya-Linderb C, Hänselerc E, Lentzb J, Vettera W, et al. Effect of orlistat on postprandial lipemia, NMR lipoprotein subclass profiles and particle size. Atherosclerosis 2005; 180: 127-35.

30 Zelber-Sagi S, Kessler A, Brazowsky E, Webb M, Lurie Y, Santo M, et al. A double-blind randomized placebocontrolled trial of orlistat for the treatment of nonalcoholic fatty liver disease. Clinical Gastroenterology and Hepatology 2006; 4: 639-44.

31 Norris SL, Zhang X, Avenell A, Gregg E, Schmid CH, Kim C, et al. Efficacy of pharmacotherapy for weight loss in adults with type 2 diabetes mellitus: a meta-analysis. Archives of Internal Medicine 2004; 164: 1395-404.

32 Kelley DE, Kuller LH, McKolanis TM, Harper T, Mancino J, Kalhan S. Orlistat on insulin resistance, regional adiposity, and fatty acids in type 2 diabetes mellitus. Diabetes Care 2004; 27: 33-40.

33 Damci T, Yalin S, Balci H, Osar Z, Korugan U, Ozyazer M, et al. Orlistat augments postprandial increases in glucagonslike peptide 1 in obese type 2 diabetic patients. Diabetes Care 2004; 27: 1077-80.

34 McDuffie JR, Calis KA, Uwaifo GI, Sebring NG, Fallon EM, Hubbard VS, et al. Three month tolerability of orlistat in adolescents with obesity related comorbid conditions. Obesity Research 2002; 10: 642-50.

35 Chanoine JP, Hampl S, Jensen C, Boldrin M, Hauptman J. Effect of orlistat on weight and body composition in obese adolescents. A randomized controlled trial. Journal of the American Medical Association 2005; 293: 2873-83.

36 DiMarzo V, Matias I. Endocannabinoid control of food intake and energy balance. Nature Neuroscience 2005; 8: 585-9.

37 VanGaal LF, Rissanen AM, Scheen AJ, Ziegler O, Rössner S, for the RIO-Europe Study Group. Effects of the cannabinoid-1 receptor blocker rimonabant on weight reduction and cardiovascular risk factors in overweight patients: 1-year experience from the RIO-Europe study. Lancet 2005; 365: 1389-97.

38 Despres JP, Golay A, Sjostrom L, for the Rimonabant in Obesity-Lipids Study Group. Effects of rimonabant on metabolic risk factors in overweight patients with dyslipidemia. New England Journal of Medicine 2005; 353: 2121-34.

39 Scheen AJ. Effects of rimonabant in patients with type 2 diabetes mellitus. Results of the RIO-DIABETES trial. Presented at the American Diabetes Association Scientific Sessions, San Diego, CA, 2005.

40 Pi-Sunyer FX, Aronne LJ, Heshmati HM, Devin J, Rosenstock $\mathrm{J}$, for the RIO-North American Study Group. Effect of rimonabant, a cannabinoid-1 receptor blocker, on weight and cardiometabolic risk factors in overweight or obese patients: RIO-North America: a randomized controlled trial. Journal of the American Medical Association 2006; 295: 761-75.

41 STRADIVARIUS (Strategy to Reduce Atherosclerosis Development Involving Administration of Rimonabant - the Intravascular Ultrasound Study). Available at http:// www.clinicaltrials.gov/ct/gui/show/NCT00124332?order_2. Accessed 30 June 2006.

42 Wadden TA, Berkowitz RI, Womble LG, Sarwer DB, Phelan $\mathrm{S}$, Cato RK, et al. Randomized trial of lifestyle modification and pharmacotherapy for obesity. New England Journal of Medicine 2005; 353: 2111-20. 